\title{
INFLUÊNCIA DA VULNERABILIDADE EMOCIONAL NA PERMANÊNCIA ESTUDANTIL EM UMA UNIVERSIDADE PÚBLICA FEDERAL
}

\author{
Maria Angélica de Moura Bueno', Lauren Machado Pinto², Maria Rita Assis Cesar ${ }^{3}$ e Júlio \\ Gomes $^{4}$

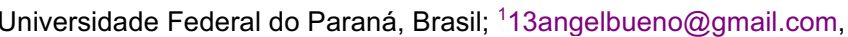 \\ 2lauren.machadopinto@gmail.com, ${ }^{3}$ prae@ufpr.br, ${ }^{3}$ mritacesar@yahoo.com.br, ${ }^{4}$ copap@ufpr.br
}

\begin{abstract}
Resumo. Apresentação de resultados do trabalho investigativo em pesquisa qualitativa resultantes do projeto de extensão sobre território ecológico do estudante ingresso (IN) na comunidade universitária pública Universidade Federal do Paraná (UFPR) pela necessidade de explorar elementos de vulnerabilidade destes. Objetiva apontar as expectativas da comunidade estudantil recém-ingressa (calouro) quanto à sua permanência universitária e preservação de qualidade de vida neste processo. A metodologia de pesquisa seguiu a participação voluntária em formulário individual com 28 itens sócio-econômicos de múltipla escolha e 1 questão subjetiva aberta no Registro Geral Acadêmico em janeiro/2019. Atendeu sigilo ético mediante aceite dos estudantes em termo de consentimento livre e esclarecido (TCLE) em convite aleatório no Registro Geral. Obteve-se aceite de 514 estudantes do quadro geral de estudantes IN UFPR. Na análise qualitativa foi alcançado evidências de atenção a categorias analíticas qualitativas concernentes à esfera de procedência sócioeducacional, aspectos culturais como rede de apoio e circunstâncias de saúde física e mental enquanto impacto nas condições de permanência universitária. Os resultados de diversidade socioeconômica, conciliação entre estudo e trabalho e fatores da rede de apoio psicossocial problematizam a conjuntura da administração pública em suas práticas de atendimento e minimização de índices de evasão e comprometimento da saúde mental observada.
\end{abstract}

Palavras-chave: Permanência; Estudante; Vulnerabilidade; Emocional; Universidade Pública.

\section{INFLUENCE OF EMOTIONAL VULNERABILITY ON STUDENT RESIDENCE AT A FEDERAL} PUBLIC UNIVERSITY

Abstract. Presentation of results of investigative work in qualitative research resulting from the extension project on the ecological territory of the student entering (IN) the public university community Federal University of Paraná (UFPR) due to the need to explore elements of the vulnerability of these. It aims to point out the expectations of the newly entered student community (freshman) regarding their university permanency and preservation of quality of life in this process. The research methodology followed the voluntary participation in an individual form with 28 multiple-choice socio-economic items and 1 subjective question opened in the Academic General Registry in January / 2019. It complied with ethical secrecy by acceptance from students in a written informed consent form (WICF) in a random invitation in General Register. Obtained acceptance of 514 students from the general board of students IN UFPR. In the qualitative analysis were obtained evidence of attention to qualitative analytical categories concerning the sphere of socio-educational origin, cultural aspects such as support network and physical and mental health circumstances as an impact on the conditions of university stay. The results of socioeconomic diversity, reconciliation between study and work, and factors of the psychosocial support network problematize the conjuncture of the public administration in its care practices and minimization of evasion rates and impaired mental health observed.

Keywords: Permanency; Student; Vulnerability; Emotional; Public University. 


\section{INTRODUÇÃO}

As Universidades Públicas Federais no Brasil têm passado por transformações na conformação do seu público de estudantes de graduação de modo acentuado desde 2005 com a instituição das cotas e ampliação do número de vagas de graduação. Isto tem por consequência o acesso ampliado com diversidade e existência de diferentes vulnerabilidades no território universitário. O projeto de extensão: "Território Ecológico do Estudante Ingresso (IN) na comunidade universitária pública Universidade Federal do Paraná (UFPR)" surge a partir da necessidade de explorar estes elementos de vulnerabilidade, considerando condições e redes de apoio do estudante ingresso na UFPR, campus sede Curitiba-PR/Brasil.

Este projeto está vinculado à Pró-Reitoria de Assuntos Estudantis (PRAE) dentro da Unidade de Apoio Psicossocial (UAPS) se constitui por equipes de apoio pedagógico, assistência social e apoio psicológico. Tendo essa base referencial, este artigo se propõe a fazer análise qualitativa dos formulários preenchidos pelo estudante ingresso (calouro) na universidade pública federal supracitada, quanto a questão de múltipla escolha sobre rede de apoio e, em especial, uma questão subjetiva aberta. Salientamos que este projeto de extensão institucional construiu internamente a logomarca (IN) como referência ao estudante ingresso calouro. Concebemos que a perspectiva qualitativa busca interpretações num determinado contexto como Oliveira, Barros e Souza (2017) afirmam que "busca interpretar os sentidos, os fenômenos e os significados que as pessoas Ihes atribuem, a partir de uma variedade de estudos empíricos, experiências pessoais, (...) que descrevem momentos rotineiros e problemáticos nas vidas dos indivíduos". (Oliveira et al, 2017, p.14)

Ao projeto surgir de parceria entre UAPS/PRAE e Núcleo de Assuntos Acadêmicos (NAA)/ Pró-Reitoria de Graduação e Educação Profissional (PROGRAD) obteve-se um sentido participativo e comunicativo de reciprocidade desde o início das atividades propostas. É a complexidade do fenômeno multidimensionado explorado no processo inteiro, na qual "uma amostra qualitativa ideal é a que reflete, em quantidade e intensidade, as múltiplas dimensões de determinado fenômeno e busca a qualidade das ações e das interações em todo o decorrer do processo." (Minayo, 2017, p.10)

Para tanto, esse artigo se propõe a identificar território ecológico da comunidade universitária federal pública pela compreensão dos impasses envolvendo a comunidade discente no momento de ingresso à universidade. Guatarri (2001) aponta que este território 
possui três dimensões interconectadas, a saber: o enfoque intrapessoal de realização subjetiva em alcance e conexão e igualmente, no contexto interpessoal e socioambiental, equiparados em igual importância. As dimensões interconectadas estão assim apontadas “(...) trata-se, a cada vez, de se debruçar sobre o que poderiam ser os dispositivos de produção de subjetividade, indo no sentido de uma re-singularização individual e/ou coletiva, ao invés de ir no sentido de uma usinagem pela mídia, sinônimo de desolação e de desespêro."(Guatarri, 2001, p.15).

\section{CONDIÇÃO PSICOSSOCIAL DE TERRITÓRIO ECOLÓGICO DO ESTUDANTE INGRESSO (IN)}

A metodologia seguiu participação voluntária dos estudantes no preenchimento de questionário individual no momento do Registro Acadêmico na PROGRAD contendo 28 questões objetivas, com múltipla escolha e 1 questão subjetiva, aberta quanto à expectativa de manutenção da permanência na universidade e quanto à preservação de qualidade de vida neste processo. Foi assegurado garantia do sigilo absoluto na identificação dos estudantes participantes mediante solicitação de anuência em termo de consentimento livre e esclarecido (TCLE) e aceitação de utilização em pesquisa científica ocorrida em janeiro/2019), ou seja, a conotação ética subjacente. Dentre 5264 de previsão de cadastramentro, obteve-se totalização de 514 estudantes, sendo 437 formulários do Registro Geral e 77 formulários do Sistema Unificado do Vestibular (SISU).

\subsection{Fatores da rede de apoio psicossocial}

Na última questão do formulário explorou-se a natureza emocional na constituição da rede de relação de apoio psicossocial pelo estudante ingresso (IN). Consideramos que a rede de apoio assinala relações sociais no entorno social, como suporte sócioemocional e/ou financeiro na sua vida pessoal e acadêmica. Sinaliza com quem a pessoa conversa e/ou "pode contar" no dia-a-dia e/ou em situações tensionantes. Estudos prévios em Almeida (2018) apontam os benefícios de uma rede de apoio mais diversificada para estudantes de graduação, na qual nossos dados corroboram. "Assim, a composição estrutural da rede denota predomínio das relações familiares, sobretudo da figura materna, além disso, um número expressivo de amigos compõe a rede destes estudantes." (Almeida, 2018, p.4)

A metodologia qualitativa exploratória do formulário constituiu em solicitar ao estudante IN que indicasse, em múltipla escolha, quantas das figuras de referência sinalizadas 
consideraria como sua rede de apoio no período de permanência na universidade. As figuras de referência referem-se a: pai; mãe; pais; irmão;cônjuge/s; namorada/o; outro/s parente/s; amigo/s; conhecido/s e colega/s; professor/a/s; vizinho/a; sozinho/a; outro/s. E na questão subsequente, indicação da frequência de contato em sua trama social, com cada uma das rede de apoio, anteriormente assinaladas. A indicação seguia uma escala de gradação progressiva similar a Escala de Likert, entre 0 a 5 , em que 0 aponta nunca e a 5 sempre.

Em relação a composição das redes de apoio discriminadas, as principais referências indicadas foram: Mãe (60,4\%), Pai (44,7\%). Em seguida, destaca-se Amigos $(35,1 \%)$ e Irmão(s) (33,5\%). Há de se levantar que o baixo registro tanto de Professor como o de Conhecidos e Colegas, em igual porcentagem (12\%), é digno de análise e investigação contínua. Isto demonstra a necessidade de investigação do nível e arranjo de relacionamento entre estudantes e grupo de professores durante a permanência acadêmica, conforme aponta gráfico 1. (exceto 4 respostas nulas do grupo de estudantes)
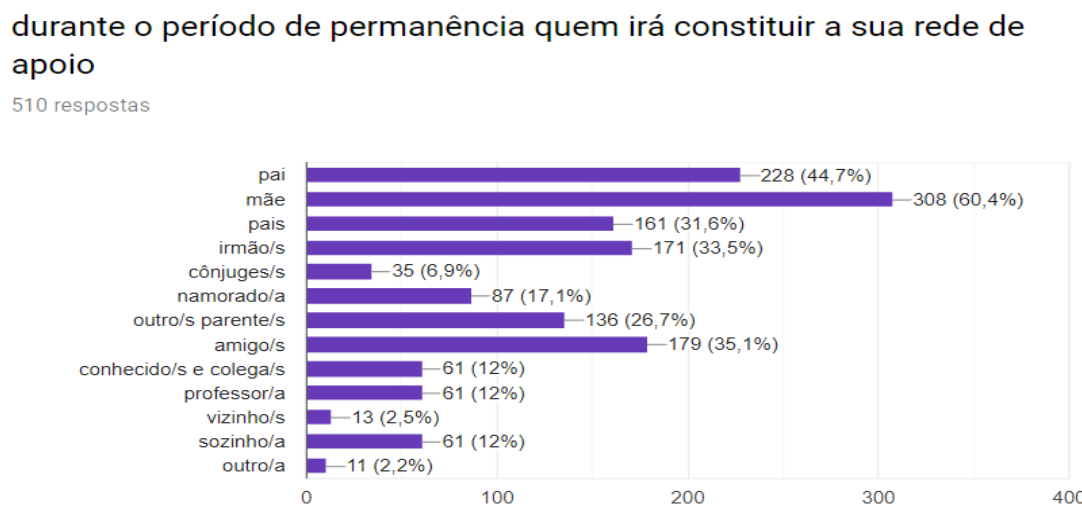

Figura 1. Rede de apoio dos estudantes Ingressantes na universidade federal pública legenda de uma figura

\subsection{Expectativa estudantil de permanência pessoal/acadêmica na universidade}

Finalmente e, de maior impacto, na análise da questão subjetiva aberta ao percrustar sobre as expectativas discentes em relação à vida pessoal/acadêmica durante sua permanência universitária visa compreensão da manutenção da qualidade de vida e derivada saúde mental. Por meio de Análise de Conteúdo, fez-se leitura exaustiva de todas as respostas a priori. Esta preparação permitiu conhecimento mais acurado sobre a realidade em causa, assim como nos permitiram a elaboração de categorias na tentativa de compreensão do fenômeno, conforme sistematização metodológica definida. 
Em cada categoria qualitativa obtida, há referência do dia de aplicação (dia I ao dia V) e indicação numérica do estudante pelo convite aleatório voluntário de participação. Ancorouse esta análise na formação de categorias baseadas na realidade social do estudante, que ancoram a realidade pessoal de modo emblemático e consequentemente interfere na condição de inclusão e permanência. Logo, com base na análise qualitativa ancoradas no contexto social do estudante ingresso apreendeu-se conexões com duas perspectivas de dimensão, ou seja, a dimensão Pessoal e a dimensão Acadêmica, intimamente correlacionadas e não excludentes entre si. Em primeiro lugar, o ponto de vista quanto a dimensão Pessoal: surgem as categorias analíticas com aspectos narrativos em Econômico, Conciliar e de Sanidade mental.

Na dimensão Pessoal do Econômico, de base econômica de sustentação vê-se na resposta do estudante V-71 sobre suas expectativas de permanência: "Estou sendo o primeiro da minha família como todo a ingressar em uma faculdade e porisso estou muito feliz. Eu batalhei muito e minha família não tem uma condição elevada mas sei que eles estão dispostos a me ajudar conseguir realizar esse sonho. Desejo me formar e poder voltar pra perto deles e ajudar todas as pessoas carentes da minha cidade e mostrar que é possível realizar seus sonhos

Ao apontar Conciliar aspectos econômicos com a realização de tarefas acadêmicas observada pelo estudante III-32: "Difícil e sem qualquer luxo, deverei me esforçar para conciliar emprego (que estou em busca) e a faculdade, pois está difícil para minha mãe me manter, já que ela tem que arcar com a sua casa, comigo e às vezes com sua mãe (que está doente).

E no tocante a preocupação com manutenção da Sanidade mental no estudante IV-109: "Espero cursar meu curso com bastante saúde mental do começo ao fim, para o meu próprio bem-estar e dos meus pacientes, uma vez que trabalharei diretamente com pessoas, cuidarei da saúde delas, não só com o que diz respeito a área odontológica. Pretendo crescer como pessoa, ajudar a ser ajudada com o contato com a população diversa, fazer trabalhos sociais, etc. Também trabalhar questões da minha ansiedade."

Estas categorias surgem em conformidade ao apontamento de Stolf (2014) da relação com a faixa etária de ingresso dos estudantes, realidade econômica do país, condições do ingresso na universidade e momento político existentes. Neste sentido, a autora aponta, que as políticas de assistência estudantil possuem histórico mutável e enfoques diferentes ao 
longo de décadas de consolidação. "Concluímos, a partir destas análises, que o desafio proposto está em superar a assistência estudantil como programa de governo (PNAES), avançando para que se torne uma política, tornando-se, desta forma, um direito de cidadania." (Stolf, 2014, p. 142)

E em segundo lugar, o ponto de vista quanto a dimensão Acadêmica: surgem as categorias analíticas ancoradas no critério de desempenho/rendimento de permanência estudantil com aspectos narrativos em Diversidade, Suporte e Aprendizado.

Na dimensão Acadêmica da Diversidade o estudante IV-36: "A UFPR sempre foi minha opção, antes mesmo de definir qual curso queria, portanto minha expectativa com a graduação é alta. Espero uma formação não apenas com a base forte, como também obter experiências que o mundo atual oferece na minha área e ainda, ter capacitação para área científica, a qual a UFPR possui muito reconhecimento."

Em dimensão Acadêmica no aspecto do Suporte, o estudante I-22: "A vida acadêmica deve ser estimulante e desafiadora, ao passo que deve também dar suporte e ampliar as oportunidades dos ingressantes. Como já passei pela universidade, e, agora, sou servidor da mesma, a infraestrutura da graduação deve ser melhorada. Em um curso como química, a atualização das disciplinas experimentais deve ser realizada."

E dimensão Acadêmica no aspecto Aprendizado o estudante II-43: "Ter apoio para me direcionar ao objetivo de conclusão do curso, seja ferramentas de aprendizado, métodos, e a próprias parcerias com iniciativa privada."

Podemos referir que nestes elementos observa-se a finalidade da existência da universidade pública, incorrendo na concomitância de objetivos, uma vez que para além da formação profissional, verifica-se a necessidade de que o período de graduação possa promover a formação cidadã e de diversidade profissional de estudantes. "Na defesa que faz da diversidade externa, Vught (2009) argumenta que a diversidade atende as necessidades dos alunos, promove a mobilidade social e satisfaz as demandas do mercado de trabalho." (Sampaio, 2014, p.45). 


\section{VULNERABILIDADE EMOCIONAL E PERMANÊNCIA UNIVERSITÁRIA}

Em relação aos dados quantitativos obtidos na pesquisa original, a configuração identidária dos estudantes que aderiram ao preenchimento do formulário questionário, destaca-se $21,4 \%$ de outro estado brasileiro. Desse modo, consideramos como sinalizador a importância da problematização do artigo quanto aos fatores de rede de apoio psicossocial serem de pouca ênfase e destaque pelos estudantes ingressantes e nas atribuições feitas à saúde mental e qualidade de vida estarem em diacronia. Esta diacronia, em nosso entendimento, refere-se ao apontamento de discordâncias e transformação desse fenômeno ao longo do tempo, portanto, merecedor de análise, interesse e práticas públicas contínuas. Significa apontamentos de continuidade de contato com estudantes no ingresso.

Neste sentido, verifica-se também que, apesar de a educação ser garantida como um direito constitucional, não há para o ensino superior a garantia igualitária a este direito. A partir da interlocução com diversidade de atores sociais tem sido buscado amenização por meio das políticas afirmativas, as quais merecem destaque as políticas de Cotas e o Programa Nacional de Assistência Estudantil (PNAES). "Nesse marco legal, a assistência estudantil é reconhecida como estratégia de combate às desigualdades sociais, ampliação e democratização das condições de acesso e permanência no ensino superior público federal, com uma definição bastante ampliada." (Imperatori, 2017, p. 298).

\section{CONCLUSÕES}

Julgamos de relevância a composição de interrelação do universo do estudante ingresso com a rede docente enquanto estrutura admnistrativa e de planejamento curricular em suas diversas fases relativa portanto, a prazos e planos de trabalho. Refere-se a equacionar de modo objetivo e dentro do tempo real de realização do curso do estudante ingresso na academia os diversos componentes que agregam permanência do estudante universitário. Intenta levantar questionamentos e argumentações quanto a produção de sofrimento do discente no meio acadêmico público universitário para questões como a individualização e psicologização das situações, ou seja, compreensão sobre processos de produção do fracasso escolar e baixos índices acadêmicos que porventura surjam, que não sejam atribuídos a fatores de ordem individualizante e patologizante por presunção. 
A vida acadêmica impõe aos estudantes o desenvolvimento de estratégias que envolvem recursos pessoais no desenvolvimento das atividades, desafios esses, ligados à formação universitária associadas a fatores singulares podem desencadear condições de sofrimento que, a interesse deste estudo, podem impactar diretamente na permanência universitária. "É importante tal constatação, considerando que o sofrimento psicológico pode ter implicações consideráveis no processo de aprendizagem e formação do futuro profissional." (Padovani et al., 2014, p.7)

Mediante essa fundamentação analítica do território ecológico do estudante ingresso (IN), pretende-se ocasionar trabalho conjunto na construção de ações que visem a permanência e favoreçam os bons resultados acadêmicos e integralização curricular relacionada ao cotidiano do público universitário ingresso. Ponderamos recomendação de estratégias para o desenvolvimento de potencialidades subjetivas e sociais relacionadas à ampliação e/ou reconhecimento das redes de apoio psicossocial com o objetivo de prevenir dificuldades que possam prevalecer estresse no cotidiano e até mesmo culminar em condições de adoecimento como rotina.

A partir do conhecimento dos indicadores psicossociais, necessário desenvolvimento permanente de revisão de fluxos, novas pactuações com coordenadores de cursos e direções de setor, associações e centros acadêmicos nos diversos campi, abrindo caminho de institucionalização da prática com estudante ingresso (IN) como política pública.

\section{REFERÊNCIAS}

Guatarri, F. (2001). As Três Ecologias. (M. C. F. Bittencourt. Trad.) (11a ed.). Campinas, SP: Papirus.

Imperatori, T. K. (2017). A trajetória da Assistência Estudantil na educação superior brasileira Serv. Soc. Soc., (n. 129) São Paulo: 285-303. Recuperado de http://dx.doi.org/10.1590/0101-6628.109

Minayo, M. C. S. (2017). Amostragem e saturação em pesquisa qualitativa: consensos e controvérsias sampling and... Revista Pesquisa Qualitativa. (Vol. 5, n. 7) São Paulo, SP, 01-12.

Oliveira, E. S. F., Barros, N. F. e Souza, D. C. D. B. N. (2017). Metodologias qualitativas em diferentes cenários: saúde e educação. Goiânia: Gráfica UFG.

Padovani, R. C., Neufeld, C. B., Maltoni, J., Barbosa, L. N. F., Souza, W. F., Cavalcanti, H. A. F. \& Lameu, J. N. (2014). Vulnerabilidade e bem-estar psicológicos do estudante universitário Rev. bras.ter. cogn. (Vol.10 no.1) Rio de Janeiro.

Sampaio, H. (2014) Diversidade e Diferenciação no ensino superior no Brasil: Conceitos para discussão. RBCS (Vol. $29 \mathrm{n}^{\circ}$ 84) São Paulo.

Stolf, F. (2014) Assistência Estudantil na Universidade federal de Santa Catarina: uma análise inicial do Programa Bolsa Estudantil. Florianópolis, SC, 156. 